This is an electronic reprint of the original article. This reprint may differ from the original in pagination and typographic detail.

\author{
Author(s): Turunen, Lotta; Pan, FangFang; Beyeh, Ngong Kodiah; Trant, John F.; Ras, Robin H. A.; \\ Rissanen, Kari
}

Title: Bamboo-like Chained Cavities and Other Halogen-Bonded Complexes from Tetrahaloethynyl Cavitands with Simple Ditopic Halogen Bond Acceptors

Year: $\quad 2018$

Version:

Please cite the original version:

Turunen, L., Pan, F., Beyeh, N. K., Trant, J. F., Ras, R. H. A., \& Rissanen, K. (2018). Bamboo-like Chained Cavities and Other Halogen-Bonded Complexes from Tetrahaloethynyl Cavitands with Simple Ditopic Halogen Bond Acceptors. Crystal Growth and Design, 18(1), 513-520. https://doi.org/10.1021/acs.cgd.7b01517

All material supplied via JYX is protected by copyright and other intellectual property rights, and duplication or sale of all or part of any of the repository collections is not permitted, except that material may be duplicated by you for your research use or educational purposes in electronic or print form. You must obtain permission for any other use. Electronic or print copies may not be offered, whether for sale or otherwise to anyone who is not an authorised user. 
Subscriber access provided by JYVASKYLAN UNIV

\title{
Article
}

\section{Bamboo-like Chained Cavities and Other Halogen-Bonded Complexes from Tetrahaloethynyl Cavitands with Simple Ditopic Halogen Bond Acceptors}

\author{
Lotta Turunen, FangFang Pan, Ngong Kodiah Beyeh, John F. Trant, Robin H. A. Ras, and Kari Rissanen \\ Cryst. Growth Des., Just Accepted Manuscript • DOI: 10.1021/acs.cgd.7b01517 • Publication Date (Web): 06 Dec 2017
}

Downloaded from http://pubs.acs.org on December 8, 2017

\section{Just Accepted}

"Just Accepted" manuscripts have been peer-reviewed and accepted for publication. They are posted online prior to technical editing, formatting for publication and author proofing. The American Chemical Society provides "Just Accepted" as a free service to the research community to expedite the dissemination of scientific material as soon as possible after acceptance. "Just Accepted" manuscripts appear in full in PDF format accompanied by an HTML abstract. "Just Accepted" manuscripts have been fully peer reviewed, but should not be considered the official version of record. They are accessible to all readers and citable by the Digital Object Identifier (DOI®). "Just Accepted" is an optional service offered to authors. Therefore, the "Just Accepted" Web site may not include all articles that will be published in the journal. After a manuscript is technically edited and formatted, it will be removed from the "Just Accepted" Web site and published as an ASAP article. Note that technical editing may introduce minor changes to the manuscript text and/or graphics which could affect content, and all legal disclaimers and ethical guidelines that apply to the journal pertain. ACS cannot be held responsible for errors or consequences arising from the use of information contained in these "Just Accepted" manuscripts. 


\title{
Bamboo-like Chained Cavities and Other Halogen-
}

\author{
Bonded Complexes from Tetrahaloethynyl
}

\section{Cavitands with Simple Ditopic Halogen Bond}

\author{
Acceptors \\ Lotta Turunen, ${ }^{a}$ Fangfang Pan, ${ }^{b^{*}}$ Ngong Kodiah Beyeh, ${ }^{c, d^{*}}$ John F. Trant, ${ }^{d}$ Robin H. A. Ras ${ }^{c}$ and \\ Kari Rissanen ${ }^{a^{*}}$ \\ ${ }^{a}$ University of Jyvaskyla, Department of Chemistry, Nanoscience Center, P.O. Box 35, 40014 \\ University of Jyväskylä, Finland. \\ ${ }^{\mathrm{b}}$ Key Laboratory of Pesticides and Chemical Biology, Ministry of Education, College of \\ Chemistry, Central China Normal University, Wuhan 430079, China. \\ ${ }^{c}$ Aalto University, School of Science, Department of Applied Physics, Puumiehenkuja 2, 02150 \\ Espoo, Finland. \\ ${ }^{\mathrm{d}}$ University of Windsor, Department of Chemistry and Biochemistry, N9B 3P4 Windsor, ON, \\ Canada.
}

\begin{abstract}
Halogen-bonding provides a useful complement to hydrogen-bonding and metalcoordination as a tool for organizing supramolecular systems. Resorcinarenes, tetrameric bowl-
\end{abstract}


shaped cavitands, have been previously shown to function as efficient scaffolds for generating dimeric capsules in both solution and solid-phase, and complicated one-, two-, and threedimensional frameworks in the solid phase. Tetrahaloethynyl resorcinarenes (bromide and iodide) position the halogen atoms in a very promising "crown-like" orientation for acting as organizing halogen-bond donors to help build capsules and higher-order networks. Symmetric divalent halogen bond acceptors including bipyridines, 1,4 dioxane, and 1,4diazabicyclo[2.2.2] octane are very promising halogen-bond accepting partners for creating these systems. This report describes the complex structures arising from combining these various systems including self-included dimers, herringbone-packed architectures enclosing medium $\left(186 \AA^{3}\right)$ cavities, and a very intriguing bamboo-like 1-D rod with large $\left(683 \AA^{3}\right)$ cavities between adjacent dimeric units. These various structures, all organized through host-host, hostacceptor, and host-solvent interactions highlight the emergent complexity of these types of complexes. As halogen bonds are weaker than hydrogen-bonds, the resulting architectures are harder to predict, and these results provide additional insight into the parameters requiring consideration when designing crystalline supramolecular systems using halogen-bonds as the core organizing principle.

\section{Introduction}

The design and construction of capsular assemblies is a growing area of focus within the supramolecular chemistry community. ${ }^{1}$ From a simple post hoc theorizing viewpoint, defined capsular assemblies should be easily designable through a complex, but deterministic evaluation of the supramolecular geometries emerging from the structure of the constituent units. ${ }^{1-4}$ However, at the nanoscopic level, the processes leading to capsule formation are considerably 
more complicated. In addition to obtaining the correct geometry by using the appropriate connecting units, ligand design and subsequent crystal engineering requires a fine control and balance between a multitude of interdependent structural, electronic and other parameters including: the strength of the bonding interactions, the size of any capsular cavity, the spatial orientation and robustness of the supramolecular synthons and interaction motifs, and the potential complicating interference from competing solvent molecules or other possible species, viz. cations and/or anions. ${ }^{1-4}$ Predicting and controlling these supramolecular interactions within a multi-component system is particularly challenging when specific capsular structures are desired. ${ }^{1-4}$ However, significant progress has been made, and the emergent behavior of these interactions is quite well understood in hydrogen bond ${ }^{5-9}(\mathrm{HB})$ and metal-ligand ${ }^{10-14}$ mediated capsular structures. The formation and control of purely halogen-bonded $(\mathrm{XB})^{15-21}$ supramolecular capsules, on the other hand, are still poorly understood and only a few examples are reported in the literature..$^{22-28}$ As halogen bonds offer a very versatile and useful complementary organizing principle to the $\mathrm{H}$ - and metal-ligand interactions, an improved understanding of these systems is required to provide the necessary tools to access ever more elaborate supramolecular architectures.

Resorcinarenes, ${ }^{29-37}$ their salts, ${ }^{38-44}$ and resorcinarene cavitands ${ }^{22-26,28,45-49}$ are well-studied families of macrocyclic receptors. Resorcinarenes are particularly useful due to their ease of preparation, simplicity of functionalization, and versatility as hosts for a wide variety of guests. $^{29-44}$ The known resorcinarene capsules formed through HBs, metal-ligand coordination bonds and dynamic covalent bonds have recently been reviewed by Kobayashi and Yamanaka. ${ }^{50}$ Concurrent with that review, we reported a novel dimeric solid-state capsule held together solely by halogen bonds (XBs) based on a pre-organized tetratopic resorcinarene XB acceptor. ${ }^{25}$ More 
recently, we have extended these studies and have demonstrated that tetrahaloethynyl cavitands act as efficient multidentate XB donors. ${ }^{51,52}$ These methylene or ethylene bridged resorcinarene cavitands, with upper rims functionalized by either four bromo- or four iodoethynyl groups, are capable of forming XBs with themselves, additional guests, and/or with solvent molecules. ${ }^{51,52}$ We envisaged that under specific conditions and using structurally suitable XB acceptors, the tetrahaloethynyl resorcinarene cavitands could form halogen-bonded capsular assemblies. In this contribution, we report halogen-bonded solid-state complexes formed between tetrahaloethynyl cavitands (Figure 1) and heterocyclic ditopic XB acceptors, 2,2'-bipyridine (2,2'-bipy), 4,4'bipyridine (4,4'-bipy), 1,4-diazabicyclo[2.2.2]octane (DABCO) and 1,4-dioxane (dioxane). These ligands are classical Lewis bases and have been used extensively in the construction of other XB architectures. ${ }^{16-21}$

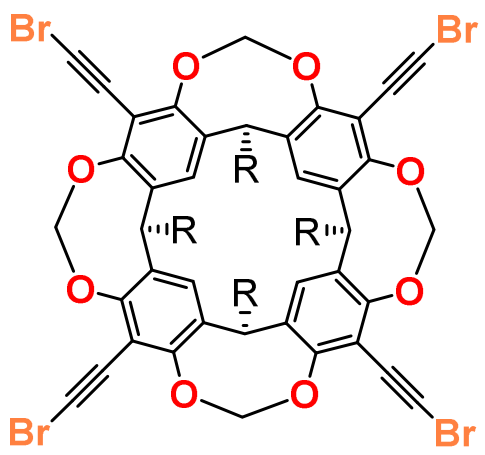

1a, $\mathrm{R}=\mathrm{C}_{6} \mathrm{H}_{13}$

1b, $\mathrm{R}=\mathrm{C}_{11} \mathrm{H}_{23}$<smiles>c1ccc(-c2ccccn2)nc1</smiles>

2,2'-bipy

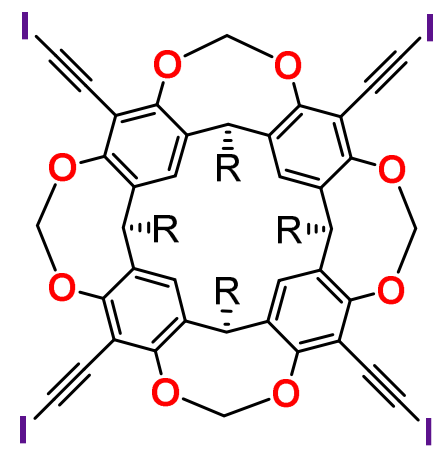

2, $\mathrm{R}=\mathrm{C}_{6} \mathrm{H}_{13}$<smiles>c1cc(-c2ccncc2)ccn1</smiles>

4,4'-bipy<smiles>C1=CNCCN1</smiles>

DABCO

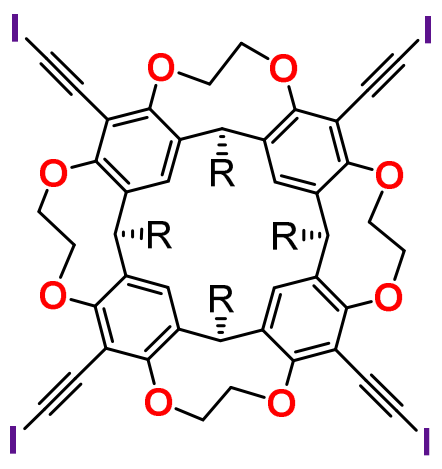

3, $\mathrm{R}=\mathrm{C}_{6} \mathrm{H}_{13}$

Figure 1. The tetratopic tetrahaloethynyl cavitand XB donors $\mathbf{1}-\mathbf{3}$ and the ditopic XB acceptors 2,2'-bipy, 4,4'-bipy, DABCO and dioxane. 
Aakeröy and coworkers ${ }^{53}$ have proposed simple guidelines to predict the halogen bonding behavior of ditopic acceptors based on the complementarity of the electrostatic potential surfaces of specific donor and guest binding sites. These guidelines work very well for systems incorporating a few relatively strong XBs. Yet it may fail in complicated systems if supramolecular organization relies on a large number of moderate XB interactions; this may be particularly true when other competing non-covalent interactions are possible. In this work, 16 examined combinations of crystallization partners, seven co-crystals suitable for single crystal Xray crystallographic diffraction were obtained, viz. 1a\&2,2'-bipy, 1a\&4,4'-bipy-A, 1a\&4,4'bipy-B, 1b\&4,4'-bipy, 2\&4,4'-bipy, 3\&DABCO and 3\&dioxane. Contrary to our expectations, many of the ditopic XB acceptors in these structures only act as monodentate XB acceptors. The obtained structures demonstrate that $\mathrm{XB}$ interactions are sufficient to organize $\mathrm{XB}$-acceptors, solvent molecules, and tetratopic XB cavitand donors into complex halogen-bonded supramolecular architectures in the solid state.

The co-crystals were obtained by mixing either $1: 1$ or $1: 2$ molar ratios of the tetrahaloethynyl cavitand XB donor and the ditopic XB acceptor (2,2'-bipy, 4,4'-bipy and DABCO, respectively) in acetone. Slow evaporation of the solvent provided single crystals suitable for single crystal X-ray crystallography. Dioxane was introduced as a potential guest by adding only a few drops into the acetone solution containing cavitand 3; 1,4-dioxaneincorporating crystals emerged upon evaporation. Our previous crystallographic analysis ${ }^{51,52}$ showed that cavitands $\mathbf{1}-\mathbf{3}$, with four haloethynyl XB donor groups have two distinct XB acceptor sites: the eight ether oxygens at the cavitand bridges, and the four ethynyl $(-\mathrm{C} \equiv \mathrm{C}-$ ) groups on the upper rim. In addition to these XB donor and acceptor sites, the cavitand has a 
cavity appropriate for small guest encapsulation. ${ }^{45-49,51,52}$ All these features combine to allow for a multitude of non-covalent

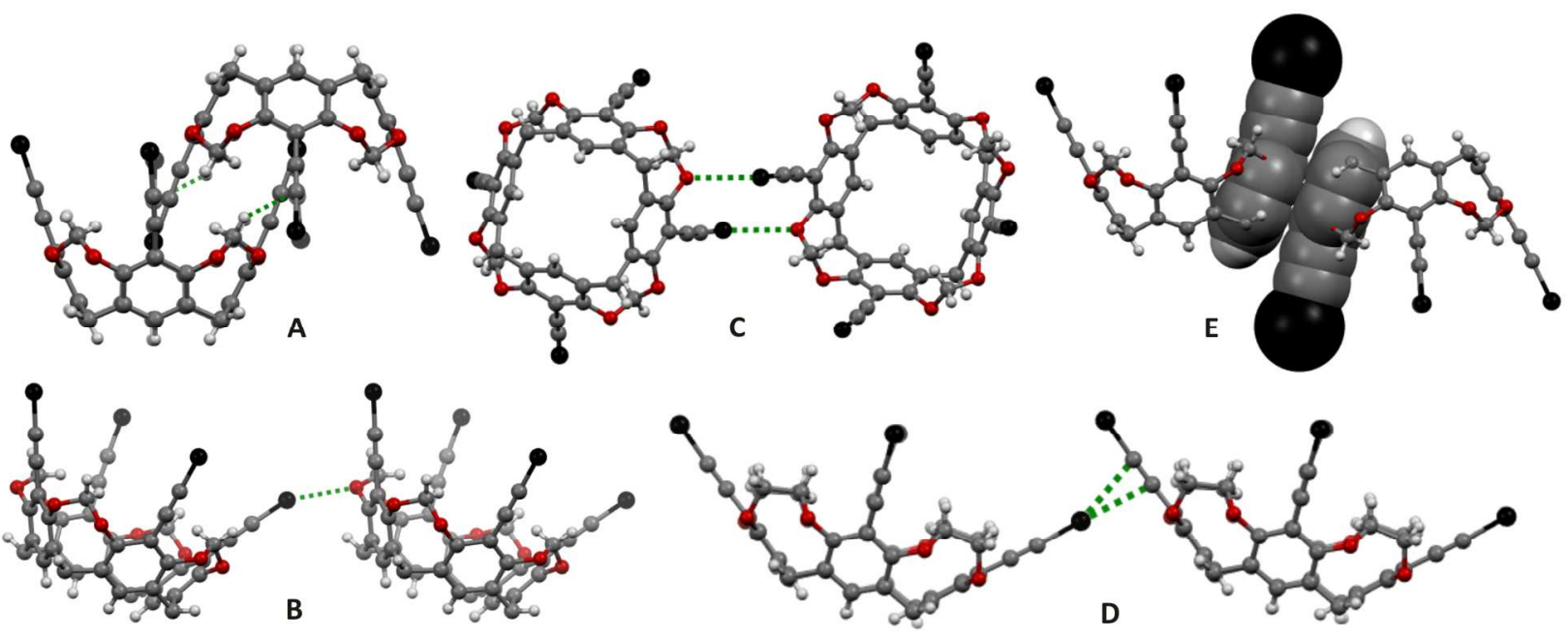

Figure 2. The weaker intermolecular binding motifs $\mathbf{A}=\mathrm{CH} \cdots \pi, \mathbf{B}=\mathrm{X} \cdots \mathrm{O}, \mathbf{C}=(\mathrm{X} \cdots \mathrm{O})_{2}, \mathbf{D}=$ $\mathrm{X} \cdots \pi, \mathbf{E}=\pi \cdots \pi$ previously observed in tetrahaloethynyl cavitands-ligand crystals (the $\mathrm{X} \cdots \mathrm{N}$ XBs not shown). ${ }^{51,52}$

interactions, especially the strong $\mathrm{X} \cdots \mathrm{N}$ XBs, but also the weaker $\mathrm{X} \cdots \mathrm{O}$ and $\mathrm{X} \cdots \pi \mathrm{XBs}$ and the $\mathrm{CH} \cdots \pi$ and $\pi \cdots \pi$ interactions (Figure 2). ${ }^{51,52}$

Based on our previous studies ${ }^{51,52}$ the major structural feature in all methylene-bridged tetrabromo/iodoethynyl cavitands (i.e., 1a, 1b and 2) solid-state structures is that they form selfincluded dimers through $\mathrm{C}-\mathrm{H} \cdots \pi$ interactions and self-complementary association between the haloethynyl groups and the cavity (motif A, Figure 2). This inserts one of the bromo- or iodoethynyl groups of each cavitand into the cavity of its partner and vice versa. These selfincluded dimers combine for six polarized halogen atoms, uninvolved in the dimerization, available to interact with other halogen bond acceptors. Consequently, co-crystallization of 1a with two equivalents of $\mathbf{2 , 2}$ '-bipy gave rise to a self-included complex 1a\&2,2'-bipy (Figures 3, $\mathrm{S} 1$ and S2). The asymmetric unit contains one tetrabromoethynyl cavitand and one and a half 
2,2'-bipyridine molecules; this self-included dimer is formally a 2:3 complex (donor:acceptor, Figure S2A) and involves no solvent (acetone) molecules. Each dimer forms $\mathrm{Br} \cdots \mathrm{N}$ XBs with four 2,2'-bipyridine molecules. One of them acts as a monodentate XB donor (Figure 3a, orange color) with one short $\mathrm{XB}\left(R_{\mathrm{BrN}}=0.89,3.04 \AA\right)$, while the second (Figure 3a, green) has two longer $\left(R_{\mathrm{BrN}}=0.92,3.14 \AA\right) \mathrm{Br} \cdots \mathrm{N}$ XBs that incorporates the dimer into a 1-D cavitand-dimer chain along the diagonal of the $a$ - and $b$-axis (Figure 3b). In the above discussion, $R$ refers to the interaction ratio, also known as normalized interaction distance, $R_{\mathrm{XB}}=d_{\mathrm{XB}} /\left(X_{\mathrm{vdw}}+B_{\mathrm{vdw}}\right),{ }^{54-56}$ where $\mathrm{X}$ represents the $\mathrm{XB}$ donor (here $\mathrm{Br}$ or I) and $\mathrm{B}$ the $\mathrm{XB}$ acceptor (here $\mathrm{N}, \mathrm{O}$ or $\pi$ ).

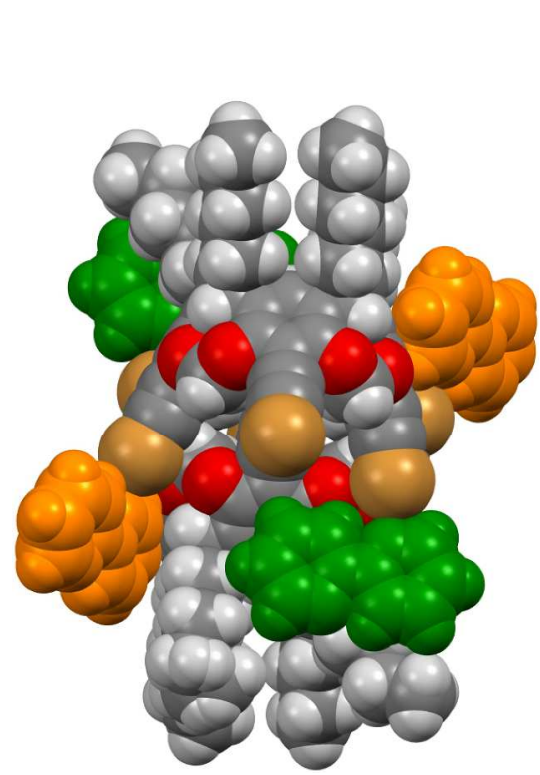

(a)

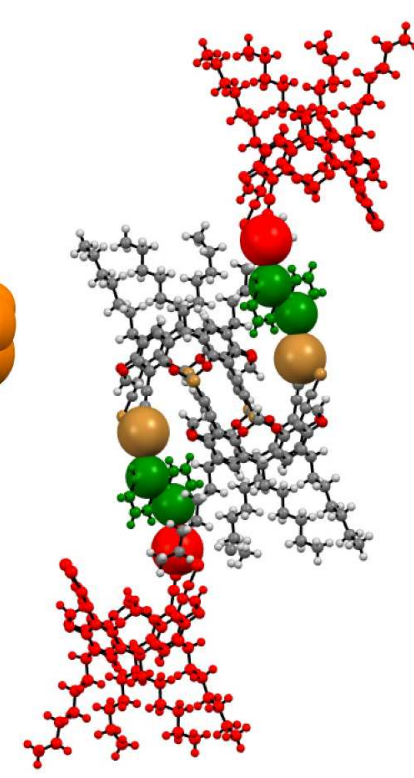

(b)

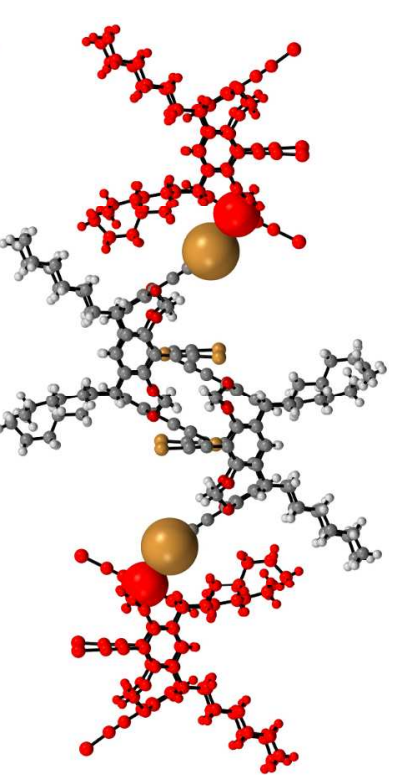

(c)

Figure 3. (a) The self-included dimer in 1a\&2,2'-bipy as a CPK presentation showing the monoXB-bipy in orange and the di-XB-bipy in green. (b) The $\mathrm{Br} \cdots \mathrm{N}$ XBs connecting the adjacent dimers shown as CPK model, diagonal of the $a$ - and $b$-axis, bromine with brown and nitrogen with green color. (c) The $\mathrm{Br} \cdots \mathrm{O}$ XBs, the $\mathrm{Br} \cdots \mathrm{O}$ XB connects two other dimers along the $b$-axis, the $\mathrm{XB}$ interacting atoms shown as $\mathrm{CPK}$, bromine with brown and oxygen with red color. 
The two remaining $\mathrm{Br}$ atoms of the dimer participate in a $\mathrm{Br} \cdots \mathrm{O}$ XB with the neighboring dimer $\left(R_{\mathrm{BrO}}=0.88,2.98 \AA\right.$, Figure $\left.3 \mathrm{c}\right)$ linking the dimers into a 1-D chain through interaction motif $\mathbf{B}$ (Figure 2), enhanced by additional inter-dimer $\pi \cdots \pi$ interactions (motif $\mathbf{E}$, Figure 2), along the crystallographic $b$-axis, similar to those observed in the previously reported solvate structures. ${ }^{52}$ Together these $\mathrm{Br} \cdots \mathrm{N}$ and $\mathrm{Br} \cdots \mathrm{O}$ XB interactions stabilize the crystal lattice (Figure $\mathrm{S} 1$ and $\mathrm{S} 2$ )

Two different structures were obtained from the co-crystallization of 1a and 4,4'-bipy, an isomer of $\mathbf{2 , 2}$ '-bipy. Depending on the XB donor to XB acceptor ratio, either 1a\&4,4'-bipy-A (1:2) or $\mathbf{1 a} \& \mathbf{4}, \mathbf{4}^{\prime}$-bipy-B (1:1) were obtained. The $\mathbf{1 a} \& \mathbf{4}, \mathbf{4}$ '-bipy-A has one cavitand and two 4,4'-bipy molecules in the asymmetric unit. Yet, as in 1a\&2,2'-bipy, it is a self-included dimer but in a 2:4 ratio (Figure 4a). As in 1a\&2,2'-bipy, six $\mathrm{Br}$ atoms are available for XBs. Quite surprisingly, only one of the two 4,4'-bipy acceptors is halogen-bonded $\left(R_{\mathrm{BrN}}=\right.$ $0.86,2.93 \AA$ ), and then only as a monodentate ligand (Figure 4a, highlighted in green). The non$\mathrm{XB}$ coordinating nitrogen atom forms a weak $\mathrm{N} \cdots \mathrm{H}-\mathrm{C}$ non-classical hydrogen bond with the hexyl chain of an adjacent dimer (Figure S4).

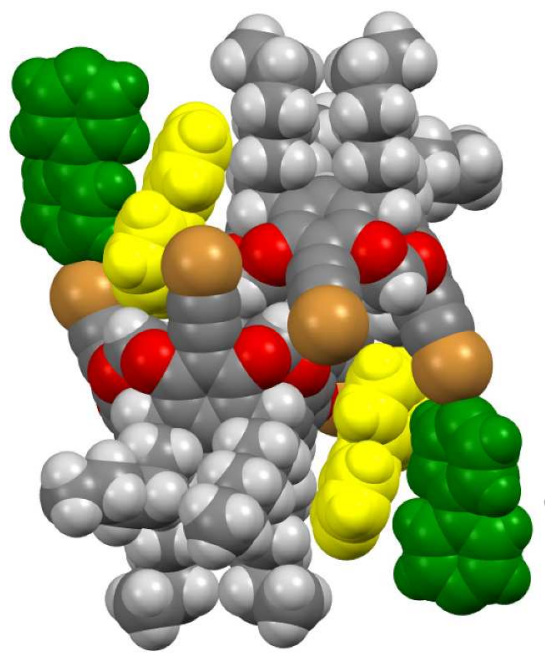

(a)

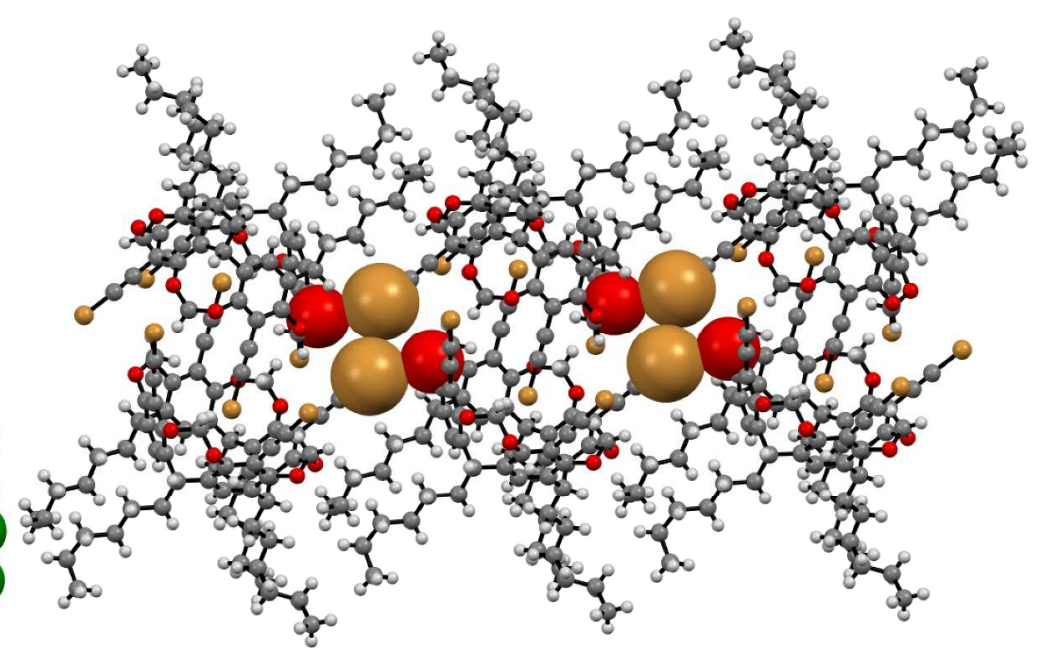

(b) 
Figure 4. (a) The self-included dimer in 1a\&4,4'-bipy-A as a CPK representation showing the

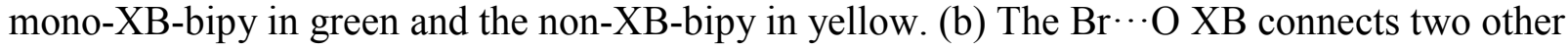
dimers along the $a$-axis, the $\mathrm{XB} \mathrm{Br}$ (brown) and $\mathrm{O}$ (red) atoms are shown as CPK models for clarity.

The second 4,4'-bipy ligand (Figure 4a, highlighted in yellow) is not halogen-bonded, but rather is trapped between the XB-bipy and the outer wall of the cavitand (Figure 4a). The non-XB-bipy does have a weak hydrogen-bond with the C-H of the cavitand's methylene-bridge. The other end forms a weak self-complementary $\mathrm{C}-\mathrm{H} \cdots \mathrm{N}$ HB dimer with the adjacent non-XBbipy, as the green bipy has the two aromatic rings twisted out of coplanarity (Figure S4C). These interactions consequently account for two of the six available bromine atoms of the dimer. An additional two of the remaining $\mathrm{Br}$ atoms both participate in two separate $\mathrm{Br} \cdots \mathrm{O} \mathrm{XB}$ to adjacent dimers $\left(R_{\mathrm{BrO}}=0.88,3.02 \AA\right.$, Figure $\left.4 \mathrm{~b}\right)$ through interaction motif B (Figure 2$)$ creating a 1-D chain of dimers along the crystallographic $a$-axis; this is similar to the systems we have previously observed in the solvate structures. ${ }^{52}$ The remaining two bromine atoms of the 1a\&4,4'-bipy-A dimer are surrounded by the adjacent 4,4'-bipy molecules and dimers and do not participate in any significant interactions.

We had expected that all of the halogens in the 1:2 (1a: 4,4'-bipy) would have been involved in interactions, and that these would have been effectively bridged by the adaptable bipy ligands. To further explore these systems, we conducted an additional experiment, using only a 1:1 ratio of the cavitand and bipyridine. This provided co-crystal, 1a\&4,4'-bipy-B. The asymmetric unit cell is comprised of one cavitand and half of a 4,4'-bipy, adopting a selfincluded 2:2 dimer architecture (Figure 5a). The 4,4'-bipy acceptor shows strong ditopic $\mathrm{Br} \cdots \mathrm{N}$ halogen bonds $\left(R_{\mathrm{BrN}}=0.81,2.76 \AA\right.$, Figure 5a, green color $)$ with the cavitand. 


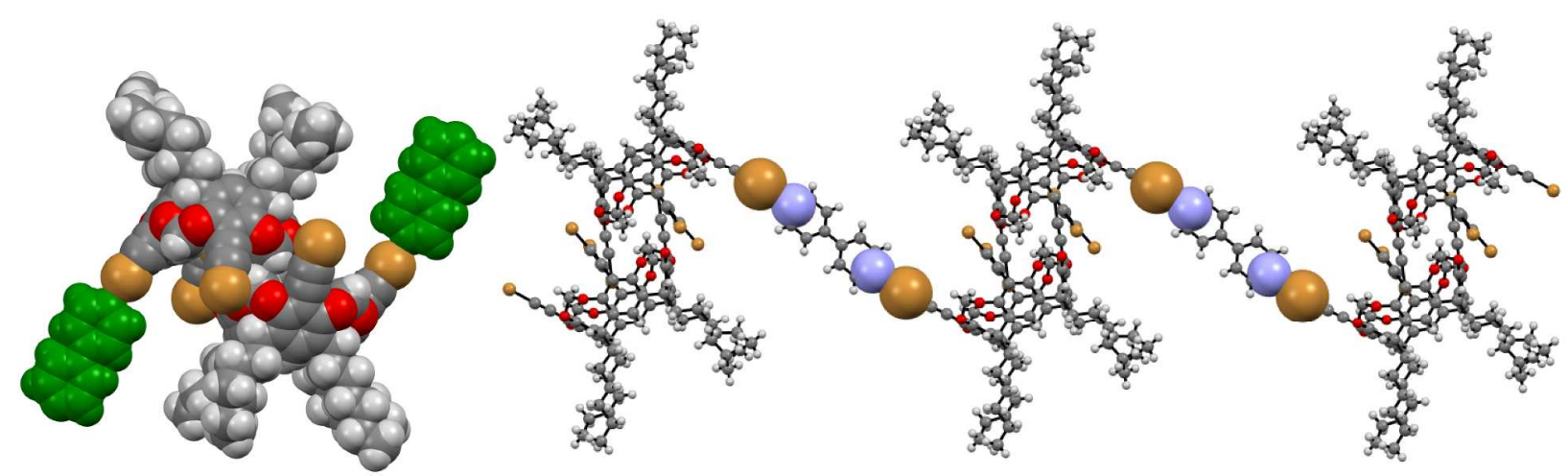

(a)

(b)

Figure 5. (a) The self-included dimer in 1a\&4,4'-bipy-B in a CPK presentation highlighting the ditopic XB-bipy (green). The $\mathrm{Br} \cdots \mathrm{N}$ XB connects the dimers along the $b$-axis, the XB $\mathrm{Br}$ (brown) and $\mathrm{N}$ (pale blue) atoms are shown as CPK models.

In this case, as there are insufficient XB acceptors present for the available donors, the Aakeröy concept ${ }^{53}$ is sustained and only the strongest donor and acceptor interact as expected. This assembles the dimers through the 4,4'-bipy (Figure 5b) into a 1-D chain along the crystallographic $b$-axis. The lack of sufficient XB acceptors present in 1a\&4,4'-bipy-B, forces the contacts between the cavitand molecules to be different from those observed for 1a\&2,2'bipy and 1a\&4,4'-bipy-A. As in 1a\&4,4'-bipy-A, the strong self-inclusion behavior and the $\pi \cdots \pi$ interactions (motif $\mathbf{E}$, Figure 2) between the dimers are preserved. Yet the $\mathrm{Br} \cdots \mathrm{O}$ XBs observed in 1a\&2,2'-bipy and 1a\&4,4'-bipy-A are now replaced by weak $\mathrm{CH} \cdots \mathrm{Br}$ bonds. Even the $\pi \cdots \pi$ stacking between the cavitand resorcinol moieties relative to the orientation of the selfincluded dimer is different (Figure S5A). It is noteworthy that, the 4,4'-bipy molecule in 1a\&4,4'-bipy-B is coplanar (deviation from planarity is only $0.01 \AA$ ). This manifests that, in addition to the expected $\mathrm{Br} \cdots \mathrm{N}$ halogen bonds, the 4,4'-bipy acts as a " $\pi$-glue" between the dimers through $\pi \cdots \pi$ interactions (Figure S5C).

The behavior of the 4,4'-bipy in the two systems 1 a\&4,4'-bipy-A and 1a\&4,4'-bipy-B, both as an XB acceptor and as an auxiliary molecule, differs considerably. To further investigate 
this discrepancy, we probed the interaction of $\mathbf{4 , 4}$-bipy with cavitand $\mathbf{1 b}$. It has the same methylene-bridged cavitand skeleton but replaces the lower rim hexyl chains of 1a with longer undecyl $\left(\mathrm{C}_{11}\right)$ groups. In the $\mathbf{1 b} \& \mathbf{4}, \mathbf{4}^{\prime}$ '-bipy crystal, the asymmetric unit contains one cavitand and two 4,4'-bipy molecules, and is defined as a self-included 2:4 dimer (Figure 6a), reminiscent to the structure of $\mathbf{1 a} \& \mathbf{4}, \mathbf{4}^{\prime}$-bipy-A. However, unlike for that system, all $\mathbf{4 , 4}$ '-bipy molecules act as two pairs of monodentate XB acceptors $\left(R_{\mathrm{BrN}}=0.83,2.84 \AA\right.$ and $0.86,2.92 \AA$; Figure 6a). One pair mediates inter-dimer organization using $\pi \cdots \pi$ interactions, while the other does not. The increased length of the alkyl substituents enhances their capability to have London dispersion force interactions, and these clearly play an important role in crystal packing. This behavior was not observed for the shorter hexyl chains in the 1a structures. The remaining $\mathrm{Br}$ atoms of the dimer participate in a very weak $\mathrm{Br} \cdots \mathrm{O}$ XBs with the neighboring dimer $\left(R_{\mathrm{BrO}}=\right.$ $0.98,3.29 \AA)$; these interactions are notable due to the unusually acute $\mathrm{C}-\mathrm{Br} \cdots \mathrm{O}$ angles of $139^{\circ}$ (normally $>170^{\circ}$ ), and link the dimers through motif $\mathbf{C}$ (Figure 2) into a 1-D chain along the crystallographic $a$-axis, as has been previously observed both above and for the solvates. ${ }^{52}$

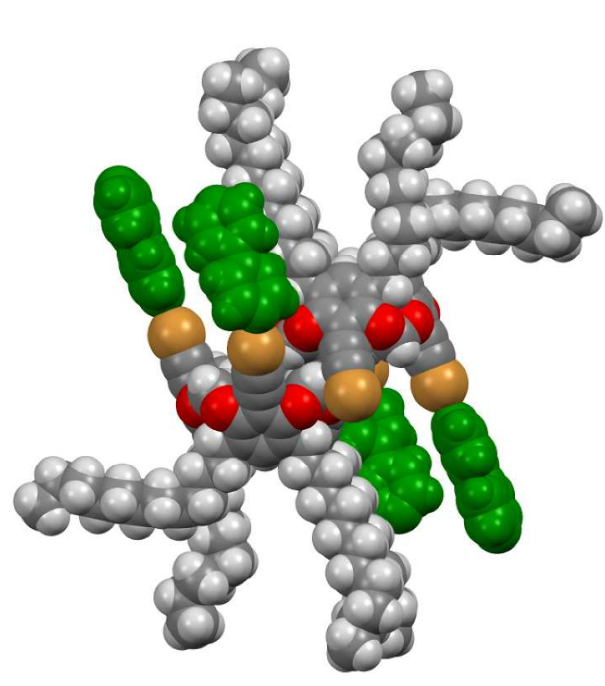

(a)

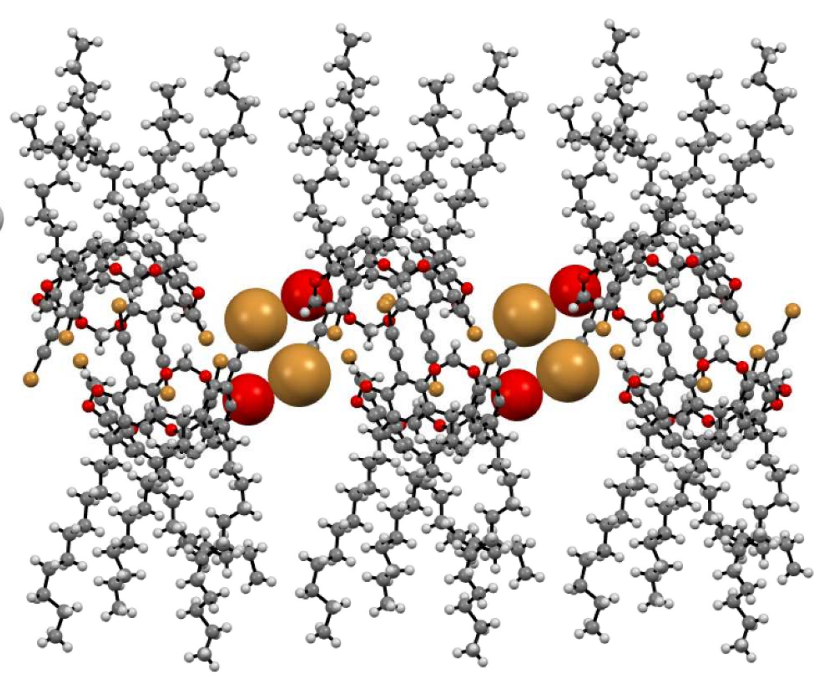

(b) 
Figure 6. (a) The self-included dimer in $\mathbf{1 b} \& \mathbf{4}, \mathbf{4}$ '-bipy presented as CPK models showing the four mono-XB-bipy (green). (b) The $\mathrm{Br} \cdots \mathrm{O}$ XB connects adjacent dimers along the $b$-axis. The $\mathrm{XB} \mathrm{Br}$ (brown) and $\mathrm{O}$ (red) atoms shown as CPK models for clarity.

Due to the more strongly polarized iodine atom, the tetraiodoethynyl cavitand $\mathbf{2}$ is able to form stronger halogen bonds with $\mathrm{XB}$ acceptors than the analogous tetrabromo cavitand 1a. Cavitand 2 is expected to show the same self-included dimer behavior, but its stronger XB potential donor should lead to other, maybe even capsular, structures with linearly ditopic XB acceptors. To investigate this hypothesis, we challenged cavitand 2 with $\mathbf{4 , 4}$ '-bipy and the resulting co-crystal $\mathbf{2} \& \mathbf{4 , 4}$-bipy is consistent with this logic, but represents a completely unexpected structure. For the first time, the crystal lattice contains the solvent molecule, yet not as an innocent bystander, but as an active component of the assembly. The asymmetric unit contains one cavitand, one 4,4'-bipy and three acetone molecules, thus the self-included dimer has a formal composition of 2:2:7 (cavitand:4,4'-bipy:acetone, Figures 7a and S6). As in 1a and 1b the self-inclusion dimer involves two of the eight available iodine atoms. The strong halogen bonds $\left(R_{\mathrm{IN}}=0.77,2.71\right.$ and $\left.2.72 \AA\right)$ between the two 4,4'-bipy molecules and four iodines of the dimer at the 1- and 3-positions organize the dimers into a 1-D rod (Figure 7c). The two remaining iodine atoms are dormant and are blocked by an acetone molecule trapped into the space between the hexyl chains of the adjacent cavitand. The strong halogen bonds force the cavitand dimers to orient themselves so that a cavity, reminiscent of the alternating cavity structure found in bamboo, is formed. This cavity is large at 


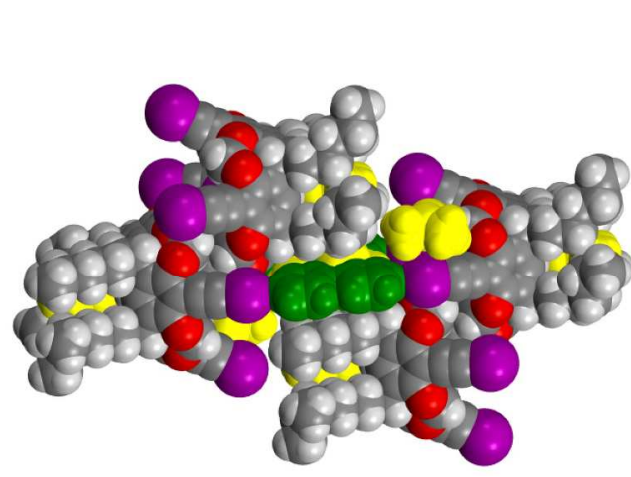

(a)

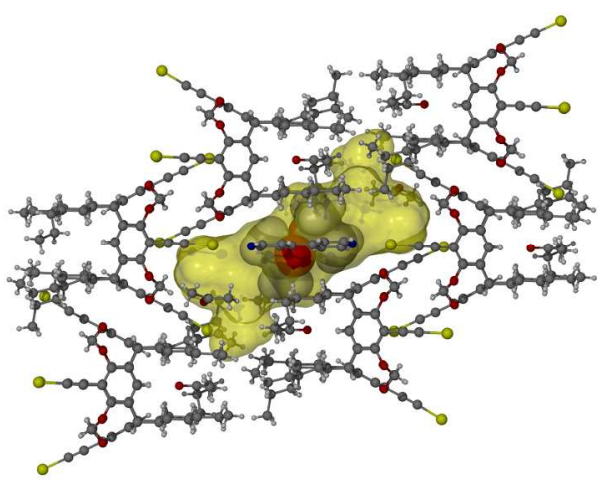

(b)

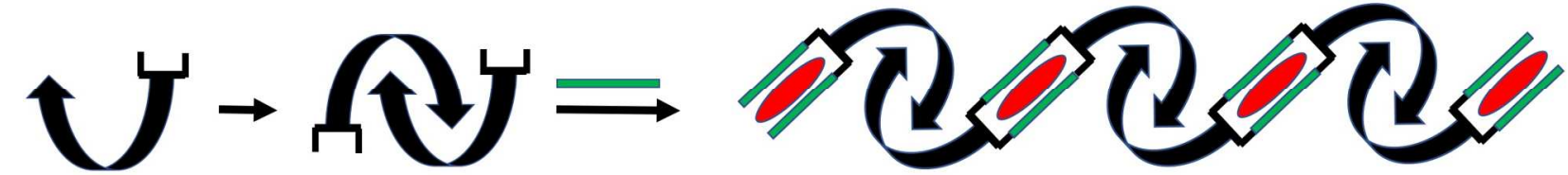

(c) cavitand $->$ self-included dimer $->$ halogen bonding $->$ the rod structure

Figure 7. (a) The halogen-bonded "dimer of dimers" in $\mathbf{2} \& \mathbf{4 , 4}$ '-bipy as CPK presentation showing the two di-XB-bipy in green and the acetone molecules in yellow. (b) The cavity in between the dimers, represented with a transparent yellow solid, the two located acetone molecules are provided as CPK models. (c) Schematic presentation of the formation of the bamboo-like chained cavities. The curved arrow represents the cavitand, the "fork" the two active iodoethynyl groups, the green rectangle 4,4'-bipy and the red oval the created cavity.

$683 \AA^{3}$, calculated using MSRoll ${ }^{57}$ inside the $X$-seed ${ }^{58,59}$ with the probe of $1.2 \AA$ (Figure $7 b$ ). The cavity is big enough to accommodate five acetone solvent molecules, two out of which are not disordered and can be localized (Figure S6). In addition to the strong XBs between the dimers, the crystal lattice is reinforced by $\pi \cdots \pi$ stacking of the 1-D rods through the interaction motif $\mathbf{E}$ (Figure 2).

All the methylene-bridged cavitands $\mathbf{1 a}, \mathbf{1 b}$ and $\mathbf{2}$ form self-included dimers due to the self-complementary fit of the haloethynyl groups with the cavity; this is accentuated by the fact that the methylene hydrogens are both acidic and pointed directly towards the center of the cavity, thus enabling $\mathrm{CH}^{\cdots} \pi$ interaction between the cavitands of the dimer (interaction motif $\mathbf{A}$, 
Figure 2). ${ }^{51,52}$ If the cavitand is constructed using the ethylene-bridge, $-\mathrm{CH}_{2}-\mathrm{CH}_{2}$-, instead of the methylene, the situation changes dramatically. Now the interactions driving the self-inclusion are greatly diminished and consequently self-included dimers are not formed. This leaves all the XB donor sites free to interact with the XB acceptors. Unfortunately, all attempts to obtain high quality single crystals from the tetraiodoethynyl cavitand 3 and $\mathbf{4 , 4}$ '-bipy were unsuccessful. However, 3 could be crystallized with DABCO by slow evaporation of the corresponding acetone solution to provide co-crystal $3 \& D A B C O$. Like 4,4,-bipy, DABCO is also a strong ditopic XB acceptor, yet it is a little bit shorter and has larger steric requirements due to its nearly spherical shape. As the $\pi$-systems of $\mathbf{4 , 4 , - b i p y ~ w e r e ~ a l s o ~ v e r y ~ i m p o r t a n t ~ i n ~ t h e ~ s t r u c t u r e s ~}$ described above, these crystals are expected to adopt rather different architectures. The asymmetric unit of 3\&DABCO contains one cavitand, two DABCO units, and two acetone molecules, such that two of the DABCO molecules are ditopically halogen-bonded $\left(R_{\mathrm{IN}}=0.78\right.$, $4 \times 2.74 \AA$ ) to two adjacent cavitands, while the remaining DABCO interacts through a monodentate XB $\left(R_{\mathrm{IN}}=0.76,2.67 \AA\right)$. An acetone molecule interacts with the remaining iodine via a $\mathrm{I} \cdots \mathrm{O}$ XB $\left(R_{\mathrm{IO}}=0.82,2.87 \AA\right.$, Figure $\left.8 \mathrm{a}\right)$. An additional non-XB acetone molecule is trapped in the space between the hexyl chains as in $\mathbf{2} \& \mathbf{4}, \mathbf{4}^{\prime}$-bipy above. As the self-inclusion does not happen in $\mathbf{3} \& \mathbf{D A B C O}$, the cavity is now open for other guests and as acetone is too polar to reside comfortably in the cavitand cavity, one of the hexyl chains of the adjacent cavitand acts as a guest and is inserted into the cavity (Figure 8b). The ditopic halogen bonds between the DABCO and $\mathbf{3}$ result in $(\cdots \mathbf{3} \cdots \mathbf{D A B C O} \cdots \mathbf{3} \cdots \mathbf{D A B C O} \cdots)_{\mathrm{n}}$ 


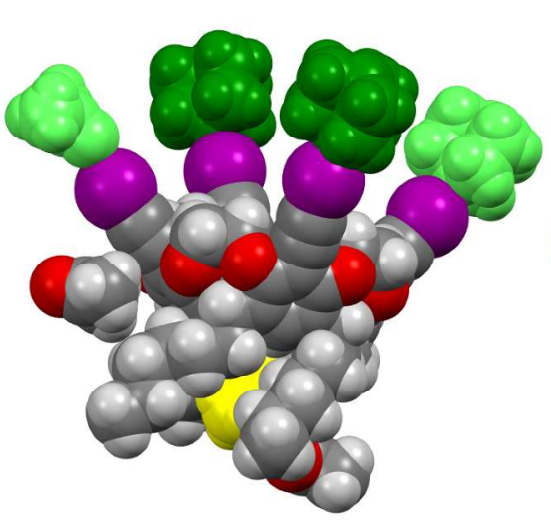

(a)

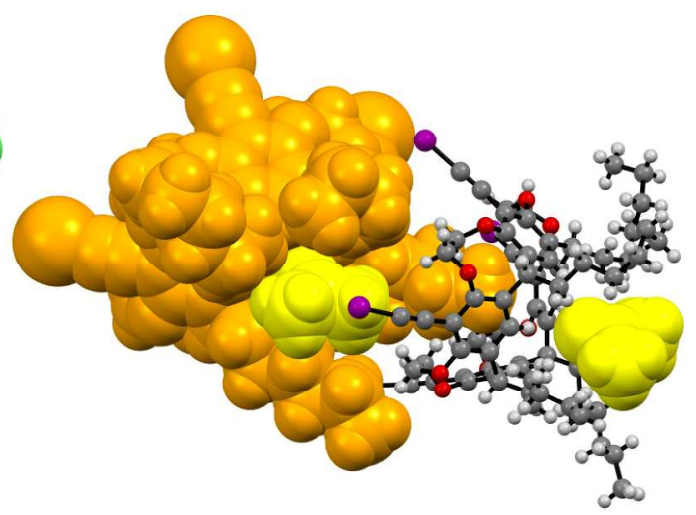

(b)

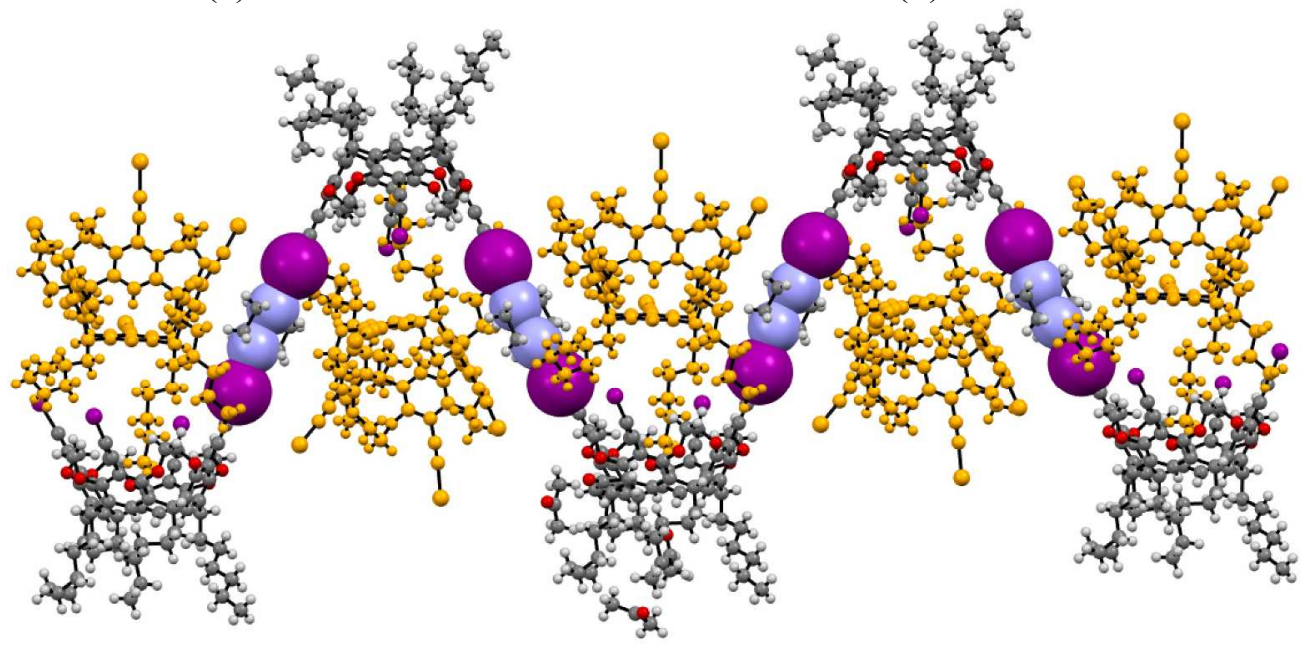

(c)

Figure 8. (a) The halogen bonding in 3\&DABCO (CPK model) showing the di-XB-DABCO in green, the mono-XB-DABCO in light green and the XB-acetone in yellow. (b) The "tailincluding" cavitand is shown as a CPK model in orange; the "binding" cavitand is shown as a ball-and-stick representation, and the acetone molecules trapped inside the hexyl rings are depicted as yellow CPK representations. (c) The XB ribbon extending along the $c$-axis, the XB donor I (purple) and $\mathrm{N}$ (pale blue) are highlighted as CPK models. The hexyl chain including in the cavitand is shown in orange with the mono-XB-DABCO and the XB-acetone removed for clarity.

"wavy" ribbons which are then joined together by the hexyl chain inclusion between the 1-D chains (Figure 8c). The C-I $\cdots \mathrm{N}$ XBs in 3\&DABCO control the interactions between the components so efficiently that none of the interaction motifs that we have become accustomed to seeing $\mathbf{A}-\mathbf{E}$ (Figure 2) are present. 
Using other quite similar solvent molecules as competitive guests, when both of them can act as XB acceptors, might lead to a situation where one solvent molecule clearly displaces the other. In spite of the similarities between the polar aprotic solvents acetone $\left(\mathrm{V}=72.7 \AA^{3}\right)$ and 1,4-dioxane $\left(\mathrm{V}=94.3 \AA^{3}\right)$, both this study (viz. in $\mathbf{2} \& \mathbf{4}, \mathbf{4}^{\prime}$-bipy and $\mathbf{3} \& \mathbf{D A B C O}$ above) and our previous data has repeatedly demonstrated that acetone does not bind in the cavity of these halosubstituted resorcinarenes; on the other hand, earlier work on other resorcinarene systems ${ }^{38-44}$ has shown that 1,4-dioxane is an excellent guest for resorcinarenes and cavitands. Keeping this in mind, the slow evaporation of tetraiodoethynyl cavitand $\mathbf{3}$ in acetone in the presence of a few drops of 1,4-dioxane (dioxane) resulted in a co-crystal, $\mathbf{3} \&$ dioxane, which crystallizes in the high symmetry orthorhombic space group $\mathrm{Cmcm}$. Due to the high symmetry, the asymmetric unit contains $1 / 4$ of 3 and 1.5 dioxane molecules. In spite of the huge excess of acetone during the crystallization, only dioxane is found in the crystal lattice. Taking into account the crystal symmetry, each cavitand $\mathbf{3}$ has one dioxane in the cavity, two acting as ditopic XB acceptors, and the remaining eight (some badly disordered) fill the voids between the cavitands. The two diXB-dioxane molecules form very strong $\mathrm{I} \cdots \mathrm{O}$ halogen bonds $\left(R_{\mathrm{IO}}=0.77,4 \times 2.70 \AA\right.$, Figure 9a), very similarly to those observed for $3 \& \mathbf{D A B C O}$ (Figure 8c), and connect the cavitands into similar 1D wave-like ribbons. Due to these strong I $\cdots \mathrm{O}$ XBs, the cavitands stack "head-to-tail" on top of each other forcing the hexyl chains to point perpendicular to the stacking axis of the cavitand columns (Figures $9 \mathrm{~b}$ and 9c) forming a herringbone-type packing (Figure 9e, only one ribbon shown). In addition to the strong cavitand-dioxane $\mathrm{I} \cdots \mathrm{O}$ halogen bonds, the $\mathbf{3} \&$ dioxane manifests very weak intermolecular $\mathrm{I} \cdots \pi$ halogen bonds $\left(R_{\mathrm{I} \pi}=0.92,3.40 \AA\right)$ and is the only structure in this study to do so (motif $\mathbf{D}$, Figure 2). These are perpendicular to the $\mathrm{I} \cdots \mathrm{O}$ halogen 
bonds joining the head-to-tail stacks together (Figure 9f). The tight head-to-tail stacking creates a cavity between the cavitands.

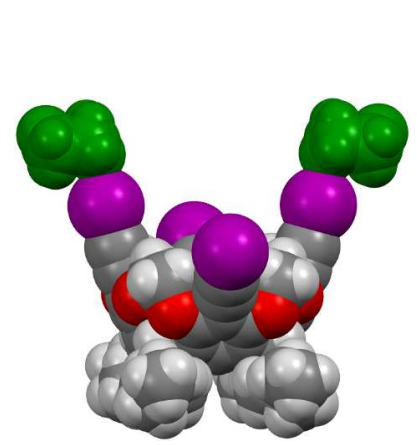

(a)

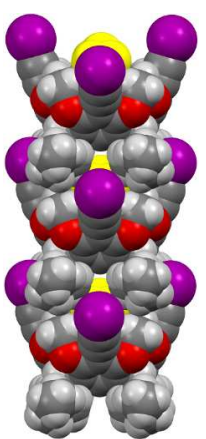

(b)

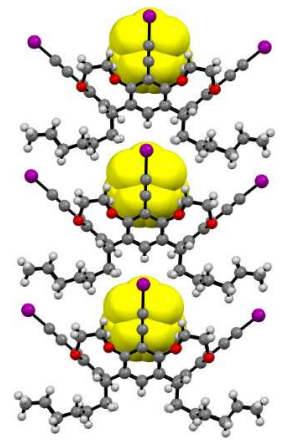

(c)

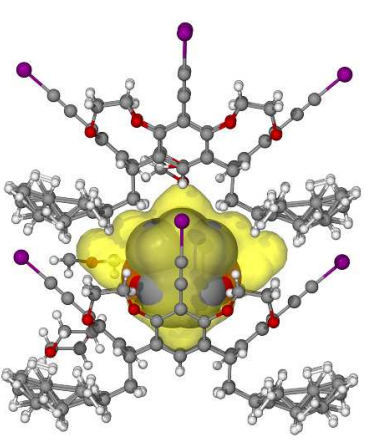

(d)

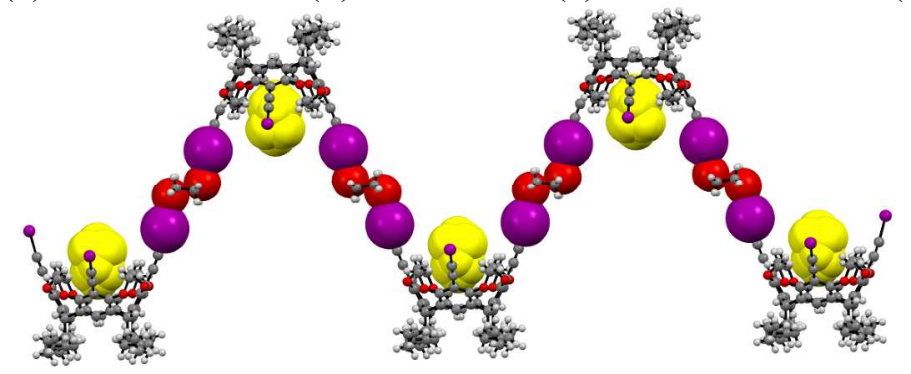

(e)

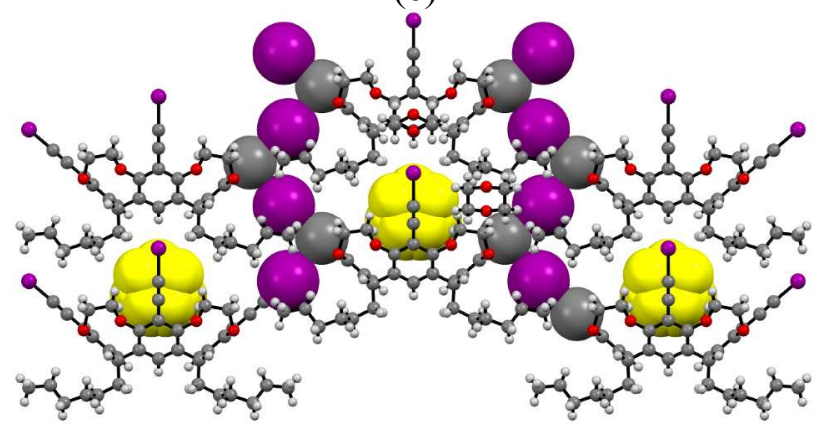

(f)

Figure 9. (a) The halogen bonding in $3 \&$ dioxane presented as CPK models showing the di-XBdioxanes in green. (b) The head-to-tail packing of the cavitands as CPK models with the encapsulated dioxane (CPK) highlighted in yellow. (c) Same view as in (b) but showing the cavitands as ball-and-stick to better illustrate the dioxanes. (d) A more detailed presentation of the inter-cavitand cavity, yellow, and the included dioxane as a translucent CPK model. (e) The $\mathrm{XB}$ ribbon extending along the $b$-axis: the XB-participating atoms are represented using CPK models, iodine (purple) and oxygen (red). (f) The independent auxiliary I $\cdots \pi$ halogen bonds, the $\mathrm{XB}$ atoms again are presented as CPK models, iodine (purple) and carbon (grey).

The cavity volume is $186 \AA^{3}$ (Figure 9d) calculated using MSRoll ${ }^{57}$ inside the $X$-seed ${ }^{58,59}$ with the probe of $1.2 \AA$. As the volume of dioxane is $94.3 \AA^{3}$, this results in a packing coefficient PC 
$=0.51$, only slightly smaller than the optimum 0.55 according to Rebek and coworkers. ${ }^{60}$ The small PC allows the dioxane molecule to tumble inside the cavity, which is observed as a severe disorder.

\section{Conclusions}

Despite the apparent geometrical and structural compatibility of these cavitand tetratopic halogen bond donors (1a, 1b, 2 and $\mathbf{3}$ ) and ditopic halogen bond acceptors, 2,2'-bipyridine, 4,4'bipyridine, DABCO and 1,4-dioxane, we were unable to obtain any simple capsules. Instead, these systems clearly prefer to self-assemble into self-including dimeric units (for the methylenebridged 1 and 2) and ribbons or head-to-tail columnar stacks (for ethylene-bridged 3). The precise structure in each case is highly dependent upon the particular nature of the ditopic acceptor and the identity of the solvent or additive. Despite the size complementarity, none of these ditopic ligands adopt a traditional guest-like posture inside the cavity of the putative hosts. However, this difficult to predict behavior results in highly exotic and intriguing architectures including self-included 1-D chains, bamboo-like alternating cavity systems, and self-organized parallel columns. These structures may prove useful for the design of innovative materials in the future, and we are continuing our investigations into the behavior of the halo-resorcinarene systems.

\section{ASSOCIATED CONTENT}

Supporting Information. Electronic Supplementary Information (ESI) available: [X-ray crystallographic details. CCDC 1574168-1574174]. This material is available free of charge via the Internet at http://pubs.acs.org.

\section{AUTHOR INFORMATION}




\section{Corresponding Authors}

*E-mail:ffpan@mail.ccnu.edu.cn; k.beyeh@uwindsor.ca; kari.t.rissanen@jyu.fi

\section{Notes}

The authors declare no competing financial interest.

\section{ACKNOWLEDGMENTS}

The authors gratefully acknowledge financial support from the Academy of Finland (KR: grant nos. 265328, 263256 and 292746; RHAR: grant no. 272579), the University of Jyvaskyla, and the University of Windsor, Canada. This work was supported by the Program of Introducing Talents of Discipline to Universities of China (111 program, B17019) and the Academy of Finland through its Centres of Excellence Programme (HYBER 2014-2019).

\section{REFERENCES}

1. Desiraju, G. R. Crystal Engineering: the Design of Organic Solids; Elsevier: Amsterdam, 1989.

2. Tiekink, E. R. T.; Vittal, J. J.; Zaworotko, M., Eds.; Organic Crystal Engineering: Frontiers in Crystal Engineering, Wiley VCH, 2010.

3. Tiekink, E. R. T.; Zukerman-Schpector, J., Eds.; The Importance of $\pi$-Interactions in Crystal Engineering: Frontiers in Crystal Engineering, 2 ${ }^{\text {ed }}$. Wiley, 2012.

4. Bond, A. D. CrystEngComm 2007, 9, 833-834.

5. Adachi, T.; Ward, M. D. Acc. Chem. Res. 2016, 49, 2669-2679.

6. Atwood, J. L.; MacGillivray, L.R. Nature 1997, 389, 469-472.

7. Gerkensmeier, T.; Iwanek, W.; Agena, C.; Fröhlich, R.; Kotila, S.; Näther, C.; Mattay, J. Eur. J. Org. Chem. 1999, 9, 2257-2262.

8. Shivanyuk, A.; Rebek, J. Proc. Natl. Acad. Sci. 2001, 98, 7662-7665.

9. Beyeh, N. K.; Rissanen, K. Isr. J. Chem. 2011, 51, 769-780.

10. Fujita, D.; Ueda, Y.; Sato, S.; Mizuno, N.; Kumasaka, T.; Fujita, M. Nature 2016, 540, 563-566.

11. Fujita, D.; Ueda, Y.; Sato, S.; Yokoyama, H.; Mizuno, N.; Kumasaka, T.; Fujita, M. Chem 2016, 1, 91-101.

12. McKinlay, R. M.; Cave, G. W. V.; Atwood, J. L. Proc. Natl. Acad. Sci. 2005, 102, 59445948.

13. McKinlay, R. M.; Thallapally, P. K.; Atwood, J. L. Chem. Commun. 2006, 2956-2958. 
14. Rathnayake, A. S.; Feaster, K. A.; White, J.; Barnes, C. L.; Teat, S. J.; Atwood, J. L. Cryst. Growth Des. 2016, 16, 3562-3564.

15. Desiraju, R.G.; Ho, S.P.; Kloo, L.; Legon, C.A.; Marquardt, R.; Metrangolo, P.; Politzer, P.; Resnati, G.; Rissanen, K. Pure Appl. Chem. 2013, 85, 1711-1713.

16. Cavallo, G.; Metrangolo, P.; Milani, R.; Pilati, T.; Priimagi, A.; Resnati, G.; Terraneo, G. Chem. Rev. 2016, 116, 2478-2601.

17. Kolář, M. H.; Hobza, P. Chem. Rev. 2016, 116, 5155-5187.

18. Wang, H.; Wang, W.; Jin, W. J. Chem. Rev. 2016, 116, 5072-5104.

19. Gilday, L.C.; Robinson, S. W.; Barendt, T. A.; Langton, M. J.; Mullaney, B. R.; Beer, P. D. Chem. Rev. 2015, 115, 7118-7195.

20. Troff, R.W.; Mäkelä, T.; Topić, F.; Valkonen, A.; Raatikainen, K.; Rissanen, K. Eur. J. Org. Chem. 2013, 2013, 1617-1637.

21. Rissanen, K. CrystEngComm 2008, 10, 1107-1113.

22. Aakeröy, C. B.; Rajbanshi, A.; Metrangolo, P.; Resnati, G.; Parisi, M. F.; Desper, J.; Pilati, T. CrystEngComm 2012, 14, 6366-6368.

23. Dumele, O.; Trapp, N.; Diederich, F. Angew. Chem., Int. Ed. 2015, 54, 12339-12344.

24. Dumele, O.; Schreib, B.; Warzok, U.; Trapp, N.; Schalley, C. A.; Diederich, F. Angew. Chem., Int. Ed. 2017, 56, 1152-1157.

25. Beyeh, N. K.; Pan, F.; Rissanen, K. Angew. Chem., Int. Ed. 2015, 54, 7303-7307.

26. Turunen, L.; Warzok, U.; Puttreddy, R.; Beyeh, N. K.; Schalley, C. A.; Rissanen, K. Angew. Chem., Int. Ed. 2016, 55, 14033-14036.

27. Turunen, L.; Peuronen, A.; Forsblom, S.; Kalenius, E.; Lahtinen, M.; Rissanen, K. Chem. -Eur. J. 2017, 23, 11714-11718.

28. Turunen, L.; Warzok, U.; Schalley, C. A.; Rissanen, K. Chem 2017, 3, 861-869.

29. Timmeman, P.; Verboom, W.; Reinhoudt, D. N. Tetrahedron 1996, 52, 2663-2704.

30. Jasat, A.; Sherman, J. C. Chem. Rev. 1999, 99, 931-968.

31. Beyeh, N. K.; Pan, F.; Valkonen, A.; Rissanen, K. CrystEngComm 2015, 17, 11831188.

32. Puttreddy, R.; Beyeh, N. K.; Rissanen, K. CrystEngComm 2016, 18, 793-799.

33. Puttreddy, R.; Beyeh, N. K.; Kalenius, E.; Ras, R. H. A.; Rissanen, K. Chem. Commun. 2016, 52, 8115-8118.

34. Puttreddy, R.; Beyeh, N. K.; Rissanen, K. CrystEngComm 2016, 18, 4971-4976.

35. Puttreddy, R.; Beyeh, N. K.; Ras, R. H. A.; Rissanen, K. ChemistryOpen 2017, 6, 417423.

36. Puttreddy, R.; Beyeh, N. K.; Ras, R. H. A.; Trant, J. F.; Rissanen, K. CrystEngComm 2017, 19, 4312-4320.

37. Kiesilä, A.; Kivijärvi, L.; Beyeh, N. K.; Moilanen, J.; Groessl, M.; Rothe, T.; Götz, S.; Topić, F.; Rissanen, K.; Lützen, A.; Kalenius, E. Angew. Chem., Int. Ed. 2017, 56, 10942-10946. 
38. Beyeh, N. K.; Rissanen, K. In Calixarenes and Beyond; Neri, P., Sessler, J., Wang, M. X. Eds.; Springer, Cham, 2016; pp 255-283.

39. Pan, F.; Beyeh, N. K.; Rissanen, K. J. Am. Chem. Soc. 2015, 137, 10406-10413.

40. Beyeh, N. K.; Pan, F.; Bhowmik, S.; Mäkelä, T.; Ras, R. H. A.; Rissanen, K. Chem. -Eur. J. 2016, 22, 1355-1361.

41. Pan, F.; Beyeh, N. K.; Bertella, S.; Rissanen, K. Chem. -Asian J. 2016, 11, 782-788.

42. Pan, F.; Beyeh, N. K.; Ras, R. H. A.; Rissanen, K. CrystEngComm 2016, 18, 5724-5727.

43. Pan, F.; Beyeh, N. K.; Ras, R. H. A.; Rissanen, K. Cryst. Growth Des. 2016, 16, 6726733.

44. Beyeh, N. K.; Jo, H. H.; Kolesnichenko, I.; Pan, F.; Kalenius, E.; Anslyn, E. V.; Ras, R. H. A.; Rissanen, K. J. Org. Chem. 2017, 82, 5198-5203.

45. Wishard, A., Gibb, B. C. In Calixarenes and Beyond; Neri, P., Sessler, J., Wang, M. X. Eds.; Springer: Cham, 2016; pp 193-234.

46. Knighton, R. C.; Chaplin, A. B. Tetrahedron 2017, 73, 4591-4596.

47. Chavagnan, T.; Bauder, C.; Semeril, D.; Matt, D.; Toupet, L. Eur. J. Org. Chem. 2017, $70-76$.

48. Gropp, G.; Trapp, G.; Diederich, F. Angew. Chem., Int. Ed. 2016, 55, 14444-1449.

49. Elaieb, F.; Semeril, D.; Matt, D. Eur. J. Org. Chem. 2016, 3103-3108.

50. Kobayashi, K.; Yamanaka, M. Chem. Soc. Rev. 2015, 44, 449-466.

51. Turunen, L.; Beyeh, N. K.; Pan, F.; Valkonen A.; Rissanen, K. Chem. Commun. 2014, 50, 15920-15923.

52. Turunen, L.; Pan, F.; Beyeh, N. K.; Cetina, M.; Trant, J. F.; Ras, R. H. A.; Rissanen, K. CrystEngComm 2017, 19, 5223-5229.

53. Aakeröy, C. B.; Wijethunga, T. K.; Desper, J.; Đaković, M. Cryst. Crowth Des. 2016, 16, 2662-2670.

54. Lommerse, P. M.; Stone, A. J.; Taylor, R.; Allen, F. H. J. Am. Chem. Soc., 1996, 118, 3108-3116.

55. Brammer, L.; Bruton, E. A.; Sherwood, P. Cryst. Growth Des. 2001, 1, 277-290.

56. Zordan, F.; Brammer, L.; Sherwood, P. J. Am. Chem. Soc. 2005, 127, 5979-5989.

57. Connolly, M. L. J. Mol. Graphics 1993, 11, 139-141.

58. Barbour, L. J. J. Supramol. Chem. 2001, 1, 189-191.

59. Atwood, J. L.; L. J. Barbour, Cryst. Growth Des. 2003, 3, 3-8. 
60. Mecozzi, S.; Rebek, J. Chem. -Eur. J. 1998, 4, 1016-1022

For Table of Contents Use Only

Bamboo-like Chained Cavities and Other Halogen-Bonded Complexes from Tetrahaloethynyl Cavitands with Simple Ditopic Halogen Bond Acceptors

Lotta Turunen, Fangfang Pan, Ngong Kodiah Beyeh, John F. Trant, Robin H. A. Ras and Kari

Rissanen

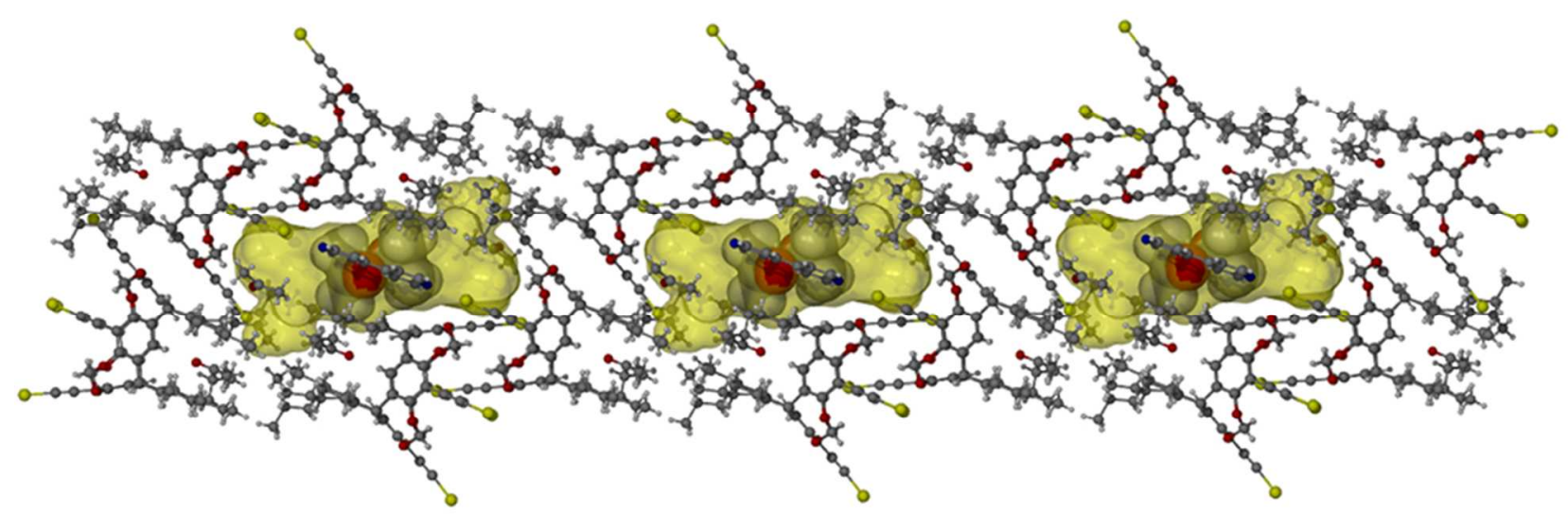

Resorcinarenes are bowl-shaped cavitands with excellent potential for host-guest interactions. In this study, halogen bond-organized systems are reported between host haloethynyl groups and ditopic halogen bond acceptors. Among numerous other reported crystal structures, including 
self-included dimers and 2- and 3-dimensional networks, a one-dimensional bamboo-like rod with large cavities was observed. 